\title{
Religious Focalisation in Dictionaries: A Comparative Case Study between English and Spanish
}

\author{
María Alonso Alonso \\ Laura Torrado Mariñas \\ University of Vigo \\ malonsoalonso@uvigo.es / ltorrado@uvigo.es
}

\begin{abstract}
The aim of this article is to expose the various strategies which are used by two of the most important dictionaries in the English and Spanish contexts, the Oxford English Dictionary and the Diccionario de la Real Academia Española, to focalise religious discourse in the main body of the definitions appearing in each dictionary. A theoretical framework on ideology and the dictionary will serve as the starting point from which to analyse these strategies and offer a classification with practical examples, dwelling on the notions of modification and focalisation. The results obtained from both dictionaries will be discussed in relation to the major strategies alluded to, highlighting the fact that the dictionary does not exist in a vacuum. As such, it is always affected by ideology in a certain degree, something which seems to support our thesis that religious discourse is one of the areas where a more pervasive presence of focalisation can be felt.
\end{abstract}

\section{Introduction}

Departing from Forgas's premise (2007: 2) about 'all lexicographical practice being [...] an ideological practice' (our translation), the present study will explore the ways in which dictionaries are indeed a highly specific kind of written discourse. What is more, 
this analysis will seek to examine the dictionary as a genre within academic materials that can be subjected to a thorough exploration of the ideological implications which may be at work in the different parts that conform such compilations of seemingly harmless definitions. The influence of dictionaries upon the social materialisation of words and concepts cannot be denied, and such an impact can be felt behind the creation of the Royal Spanish Academy (RAE, from the Spanish acronym) in 1713, which was born with the clear aim of defining the voices and words of the Spanish language in relation to their most proper, elegant and pure way.

Leaving aside the well-known existing conflict of paradigms, it seems rather obvious that the complex network of interests that bind language and society may be observed through a detailed analysis of the various lexicographical practices applied in the different dictionaries under study. At this point, it may be useful to mention that we speak of a complex network of interests because ideology is inextricably linked to what van Dijk (1996: 20) labels 'group interests', a fact which causes conflict and power struggles in many occasions.

Bearing in mind the Chomskyan postulate that considers that language may affect thought and the way in which we perceive reality, it does not seem difficult to infer that the role played by dictionaries in society must be seriously acknowledged in order to critically consider any type of ideology transmitted via the institutional entities in an objective way. One of the main motivations for writing this study stems from our belief that dictionaries can be used as 'powerful socio-political weapons [which] turn religion into one of the areas of reality where subjectivity and individual credos are reflected' (Rodríguez Barcia 2004: 1417). Thus, analysing religious focalisation in dictionaries has been considered as a highly pertinent venture when it comes to comparing ideological practices in both English and Spanish monolingual dictionaries. To do so, the iconic image of the 'focus', together with the strategy of 'focalisation', will be used to refer to the perspective from which the definition is produced and to adduce the narrative strategies employed to convey such idea. We will argue that any definition will imply an inherent or explicit adhesion to a specific religious group.

The primarily Roman Catholic character of the Spanish tradition in the field of lexicography has been widely recognised, but has the Anglophone tradition - and especially that of the British Isles - been reflected in the same way in English dictionaries? So as to contrast the possible ideological parallelisms between the Roman Catholic and the Anglican credos, the study of a corpus comprising key religious words was proposed. These were analysed bearing in mind the different strategies of modalisation applied when providing the definition of the word in question. In order to compile our corpus, the study of the religious lexicon present in the different dictionaries of the Royal Spanish Academy made by Sánchez García (2009) has been highly useful, although other specific words - more closely related to the Anglican tradition - have been added for the sake of a more thorough comparison of focalisation practices in dictionaries from both cultural backgrounds. Since no institution equivalent to the RAE exists in the Anglo-Saxon world, the Oxford English Dictionary 
(henceforth, $O E D$ ) has been used as the primary source of linguistic usage in English due to its recognised prestige in the academic world.

To structure our analysis, each dictionary's microstructure was considered while leaving other highly interesting macrostructural details aside for future research such as prologues or the selection of words that entail a high ideological charge in most cases, since they require an open positioning on the lexicographer's part. What is more, two institutional dictionaries, ${ }^{1}$ published in the 1980s, will also be analysed in the present project, although these diachronic references will be exclusively employed to highlight those specific aspects in the evolution of the discursive strategies applied to the text that modalise its religious focalisation in a sense or another.

After having introduced a theoretical framework to support our hypotheses, the present study will offer a description of the materials and the methodology employed, followed by a classification of the corpus findings. This classification was prepared taking into account the discursive strategies that shape each of the dictionaries' definitions that make their underlying religious ideology evident by means of the modalisation of discourse. Eventually, before offering the conclusions derived from such an analysis, the results obtained will be compared and contrasted in an attempt to elucidate the degree of confessional focalisation present in both Spanish and English dictionaries.

\section{Ideology and dictionaries}

The present study departs from a series of theoretical concepts, like those of ideology, culture and religious focalisation, to which it has been considered advisable to devote a few lines insofar as they can mean rather different things to different people. Their plural character - or rather their flexibility to adapt to the context of use - endows them with a high degree of ambiguity and thus, this section on ideology and dictionaries will start by clarifying what we mean when using words like the aforementioned ones.

Let us start by the very term of lexicography itself, which is usually referred to in the Diccionario de la Real Academia Española (henceforth, DRAE) as 'the art or technique of composing dictionaries'. Such dictionary clarifies the discipline's scientific character in its second entry, which explains that lexicography is 'the part of linguistics that deals with the theoretical principles in which the composition of dictionaries relies'. Therefore, it does not seem difficult to acknowledge that, being a science, lexicography should be rid of any ideological charge whatsoever. Nevertheless, the neutral character of lexicography has often been blurred by other considerations, to the extent that some critics do question its scientific value. Among these, we could single out Marcos Marín (1980: 436), who claims that

[1] exicography [...] is not a science. It is an art, a technique if you may, with a practical and concrete object, which is condensed in the volume of the dictionary once it is finished. 
Such negative opinions are mostly grounded on the fact that archaic lexicographical practices involved random and obscure processes of word selection and definition. However, modern lexicography, which began in approximately the late sixteenthcentury, has certainly earned its place as a recognised scientific discipline. Furthermore, the last twenty years have seen an incredible development of critical schools in the area due to the renewed interest in theoretical and descriptive works on dictionaries, their history and methods, and their functions or typology. Thus, we can now talk not only about lexicography as described by the $D R A E$ in the previous paragraph, but also about metalexicography; that is, the purely theoretical field of lexicography which seeks to answer the question 'What is a dictionary?' by examining not only the volume itself, but also the very process of research that precedes its constitution as such. Ideology, as we will see in this article, is therefore one of the objects of study of metalexicography, a fact which helps to answer many questions regarding not simply the elaboration of the volume, but also its subsequent interpretation by prospective readers.

Once the definition of lexicography has been clarified, the next key concept that needs to be addressed is ideology. Traditionally, the term has been defined as the set of ideas that include beliefs, values and attitudes which are used by a certain group to promote their interests. As Johnson (1995: 137) acknowledges, these beliefs and ideas 'underlie, and thereby to some degree justify and legitimate either the status quo or the movements to change it'. Such a definition brings to the forefront an important factor of any ideology: the fact that all ideologies are socially-constructed systems of thought that need to be shared by the individuals belonging to a specific group of social agents.

So far, we have established that an ideology is a system of beliefs with an essentially shared character, but we have not referred to two important factors in relation to this concept. The first of them is that ideology does not refer to any specific type of socially-shared knowledge, but to the most basic and axiomatic one which is also the matrix of social practices, so to say. As van Dijk (2005: 10) points out, this axiomatic character of ideologies helps them to control and organise other sociallyshared beliefs, so that a racist ideology may control immigration attitudes and a feminist one can condition abortion policies in society. The second important factor is the sociocognitive side of ideology, that is, the fact that ideologies are gradually acquired and may evolve with time. Hence, all ideological considerations need to be examined within a specific context, be it cultural, social or temporal.

In order to link ideologies and the domain-specific social attitudes they control to text and oral language - or, in our case, to the dictionary - van Dijk postulates that a cognitive interface is needed so as to be able to translate the general to the specific, or what is the same, social attitudes to personal opinions and general knowledge to personal knowledge about current events and situations. He further states that

[t]his interface is formed by models, as stored in episodic (personal) memory. Models are mental representations of personal experiences of specific actions, events or situations (hence also called 'situation models', 'event models' or 'episodic models'). (van Dijk 1995: 251) 
Van Dijk's claim effectively links ideologies and other social representations with discourse meaning and discourse analysis. What is more, being on the edge of social and personal cognition, models are mental representations that can be used both for producing and interpreting language and, as such, their influence in both the preparation of dictionaries and its subsequent reception should not be underestimated. The logical conclusion behind the Model paradigm posed by van Dijk is that these models, being subjected to ideological attitudes, may very well be biased, implying a series of generalisations that may confirm stereotypes and prejudices in the most unexpected and unobtrusive ways.

Models provide an attractive theoretical explanation when it comes to linking discourse analysis, ideology and lexicography insofar as they provide the common matrix around the study of the many ways in which hard facts, like the notion of religion, church or state, may be altered to suit collective considerations.

When analysed in relation to lexicographical practice, ideology needs to be understood as a powerful weapon that shapes the way in which words are conceived in a given language. Considering that Slobin's 1987 theory of 'Thinking for Speaking' postulates that each person perceives the world in a different way depending on the language they are raised in due to the fact that each language possesses a certain number of spatial, semantic, lexical and even pragmatic distinctions specific to that language, the intrinsic power of dictionaries is made a little more evident. In this context, Chomsky's (1968) widely-known statement about language being a filter of thought immediately comes to mind, ultimately reminding us of the need to look for strategies in the dictionary that point to specific moral or cultural considerations which may inscribe a particular dictionary within a given ideological group.

Before dwelling on the definition of dictionary in relation to ideology and religious focalisation, it may be worth highlighting the fact that traditional scholarship has commented on the semantic tendency to automatically ascribe positive terms to the groups we belong to and their members (in-groups), as well as to apply negative ones to the natural counterparts of these (out-groups). Such idea is supported by the studies on social cognition carried out by Fiske and Taylor (1991) and Hamilton and Sherman (1994). Even though such a tendency will be observed in more detail in the results section of this work, it is important to state at this point that the aforementioned pattern is not exclusively applied to the names and adjectives that qualify headwords, but, in some cases, to the context of the definition itself.

Let us now consider the very definition and function of dictionaries. As Anglada Boix (1991) explains, the dictionary's object is a complex one, just as lexicography is a complex practice. The present work departs from the premise that dictionaries include and exclude much about the lexical items they define, conveying at times pieces of information which are more socio-cultural than linguistic practices in character. However, it is interesting to mention that most of the classic studies on lexicography tend to avoid commenting on the way in which most dictionaries mirror the culture in which they are produced. Taking such consideration into account, it is our purpose to broaden traditional definitions of the word 'dictionary' as a compilation of word 
definitions in alphabetical order and include in such description other aspects, such as its value as a discursive shaper of reality.

To introduce the discussion, we will follow Anglada Boix (1991: 8), who expands Quemada's 1987 study and qualifies any dictionary as having a three-fold purpose:

(1) Being a communication instrument to the service of a specific informative or didactic programme.

(2) Configuring a systematised documentary whole, since it must assure the catalogue function inherent to any dictionary.

(3) Being a technical and commercial product, conditioned by the technologies available, the methods applied to it (such as typography, computer science, etc..) and by the commercial strategies adopted for its promotion.

Both Anglada Boix and Quemada attempt to emphasise the dictionary's strong connection to the book industry, with all the implications that such ties embody. However, we consider that these three points accurately point out some of the issues which will be explored and contested in this article: the fact that the dictionary is a manufactured item subjected to a didactic or informative aim, the question of its specific weight as a figure of authority and the issue of its constituting a marketable product which can be tampered with to suit commercial interests.

Geeraerts (2007: 1166) acknowledges that most dictionaries are based on structuralist theories which postulate that meaning should be defined following some basic characteristics which have to be necessary, general and distinctive. Thus, a denotative meaning should not inevitably make contextual questions explicit and yet, many of the definitions offered in dictionaries may conflict with that theoretical basis due to the fact that it is not unusual to find contextual features alongside the definitions.

Apart from these prototypical meanings, some dictionaries mark attitudes or judgments on the implicit author's part by means of the inclusion of connotative marks. These marks' pejorative, ironic or even sympathetic character adds a range of semantic values to each headword's meaning. Since a thorough overview of these strategies will be given in the following section of this work, it is enough to mention them at this point so as to draw our attention to the various ways in which the apparently neutral character of dictionaries can be altered.

Providing a definition for a word is one of the most difficult areas of lexicography, and the theories regarding by which standards such practice should abide are numerous. Some critics, among whom we could single out Hernández Hernández (1991), Trujillo (1994) or Geeraerts (2007), consider that definitions should not mingle data in relation to meaning, sense and use, therefore attempting to simply describe the word in the most aseptic manner possible. Others, like Dubois (1970), Ball (1998) and Medina Guerra (2003) recognise these traits' potential in providing a more accurate description of the word under study. As we can see, cognitive linguistics justifies the 
inclusion of connotative and contextual features insofar as the close relation between semantics and pragmatics should not be overlooked when struggling to produce a complete definition.

Researchers have come to realise that the dictionary acts as a filter, working in the same ways as Chomsky postulated that language operates and it does not list in a neutral way all the words that are in usage. It sometimes happens that commonly-used words fail to appear in the macrostructure of the dictionary; in other cases, the words do figure in the macrostructure, but their treatment within the microstructure leaves many blank spaces unanswered. Eventually, when grouping such appearances, disappearances and nuances of meaning together, one discovers that what all these words have in common is their somehow ideological character.

According to Jean-Pierre Beaujot (1989: 80), the editorial restrictions often cited to justify the absence of a given number of lexical units always hide an ideological choice. As we have been attempting to present here, the dictionary operates through visible and hidden strategies that effectively reflect the sociolinguistic norm and the prevailing ideology of a group, be it cultural, ethnic or even commercial. Therefore, scholars like Ball (1998), or in the Spanish context, Aliaga Jiménez (2000), have directed their research towards the examination of the actual consequences that this semantic selection, so to say, has on certain minority groups like homosexuals or minority-language speakers. Nevertheless, the concern for a possible focalisation of religious terms has not yet been explored in depth in the literature, leaving an interesting area to be discussed in future research.

As we can deduce from all the aforementioned considerations, the interrelation between ideology and dictionary is a complex one, in which many variables are involved. Rey and Delesalle (1979: 10) have summarised this dilemma as the conflict between the 'linguistic and semantic pole' and the 'socio-historic and cultural pole'. This notion proves to be especially useful when attempting to study the ways in which religious discourse is focalised in dictionaries coming from such separate traditions as the Roman Catholic and the Anglican one are. We need to be conscious of the fact that dictionaries try to represent the highly complex process known as language, but they are neither created in a vacuum nor exist in one, so that all lexicographic practice is in one way or another permeated by personal, collective, temporal and even context-dependent considerations that affect the way in which objective realities are described.

\section{Materials}

There are many more parallelisms between English and Spanish lexicography than may appear at first sight. As with most significant developments of our era, Humanism and the invention of the printing press constitute a turning point in the appearance of many projects, bilingual and monolingual, worldwide. Contrarily to what many lexicographers believe, monolingual dictionaries have a much more widespread tradition outside Europe, as Béjoint (1994: 93) acknowledges. Nevertheless, in the 
context of Europe, it was the appearance of bilingual dictionaries with a didactic purpose what gave rise to a number of increasingly defined projects on the part of medieval lexicographers. The height of this type of dictionaries was probably motivated by commercial interests, first due to the relevance of the import-export markets and later due to the interest of the printing presses in the economic profits which stemmed from the market of Foreign Language Learning by means of vocabulary and grammar books.

\subsection{Brief survey of English and Spanish lexicography}

Since this study presents an essentially comparative nature, we will start by providing a concise review on the history of dictionaries both in the Spanish and the Anglophone British contexts to then move on to describing the volumes which will be employed in the analysis of corpus of selected religious terms ${ }^{2}$. Since the development of Spanish lexicography influenced the way in which this discipline evolved in the British context, we will start with the Spanish tradition of dictionary-making, leaving aside the prolific works of Nebrija for the time being, since these will be addressed in a further section of this study when dealing with Anglo-Saxon bilingual dictionaries.

Rodríguez Barcia (2005) carries out a helpful survey of Spanish monolingual dictionaries, placing special emphasis on the Tesoro of Covarrubias so as to analyse some ideological aspects which are present in this book. One of Barcia's most significant contributions is its mentioning a series of lexicographical projects which have stemmed from the fifteenth century onwards, and which have been mostly overshadowed by the specific weight in academic terms of Covarrubias's work in the history of Spanish language dictionaries. Before the publication of the Tesoro there had appeared other works which most likely influenced the concern for etymology that fuels up Covarrubias's dictionary, such as the Compendio ${ }^{3}$ by López de Tamarid, published in 1585 .

But the Spanish lexicographical production which irremediably calls our attention the most is Covarrubias's Tesoro, thanks to the information it conveys not only from the point of view of its microstructure, but also from the point of view of the prologue that precedes the work. From an ideological standpoint, this monolingual dictionary is highly interesting due to the various extra-linguistic and cultural elements that mark its evident etymological and ideological positioning, which Rodríguez Barcia (2005: 11) relates to 'its natural tendency to extensively comment on extra-linguistic aspects, almost in a pseudo-encyclopaedic way'. At the same time, after the founding in 1713 of the Real Academia Española de la Lengua, the figure of Terreros y Pando gains prominence thanks to his two most important oeuvres, the Diccionario de Autoridades and the Diccionario Castellano, which 'aspire to take a census of the lexical component of the common cultivated language, found in the literary practice of good authors and in the oral production of cultivated speakers' (our translation), as Azorín and Santamaría (2004: 50) recognise. It is important to recall the direct repercussion of all these initiatives on the projects later entertained by the Real Academia, whose dictionaries 
will be employed in the present work so as to study the ideological modalisation of the 1984 volume.

In the Anglo-Saxon context, the English language has been intimately conditioned by the Norman Conquest of 1066 and the subsequent disappearance of Old English. As it happened in the Iberian Peninsula, the first English proto-dictionaries were motivated by commercial and didactic reasons, a fact which, together with the United Kingdom's insular character, accounts for the appearance of a great number of bilingual dictionaries. These bilingual dictionaries helped, on the one hand, to re-establish Middle English as a prestige variety after the Norman language dominance and, on the other, boosted the trade possibilities of an island which did not manage to take off economically at the time.

The Oxford History of English Lexicography opens up with a rather illuminating chapter on medieval glosses and glossaries, where we learn that the first author who named his compilation Dictionarius was John of Garland in the early thirteenth century, but it took quite longer for the word to become used. What is more, the large and popular Latin dictionaries from the Middle Ages have titles such as Elementarium (for beginners), Derivationes (assembling word-families) or Catholicon (a comprehensive collection). The term dictionary came to be used more frequently in the course of the seventeenth century.

Significant early attempts at producing coherent monolingual English dictionaries are Robert Cawdrey's 1604 A Table Alphabeticall ... of hard usuall English wordes, borrowed from the Hebrew, Greeke, Latin, or French, etc. ... gathered for the benefit and help of Ladies, Gentlewomen, or any other unskillful persons, Nathan Bailey's Universal Etymological English Dictionary (1721), or JK's A New English Dictionary (1702), which Osselton (2008: 137) considers to have

established once and for all the practice of including the everyday vocabulary of English alongside 'harder' words: his letter D begins with a dab, a dab-chick, a dab-fish, to dabble, a dace, and a daffodell, and at the word girl he starts with the common meaning ('A Girl, or wench').

Despite the value of these volumes as early lexicographic efforts, Johnson's 1755 Dictionary will be the most influential one well into the nineteenth century. It is the first to include citations from literature, as well as providing full vocabulary coverage in a most precise matter, which was not exempt from ideology. After Johnson, lexicographical practice had to wait for almost a century and a half to produce the dictionary that has marked English scholarship until our days, the $O E D$, first published by J. A. H. Murray et al., which included historical references alongside literary citations and a useful prologue. Despite the popularity of other dictionaries, such as the Merriam-Webster (first published in 1933 including quasi-encyclopaedic definitions with a high intrinsic discursive value) or the more recent Collins Cobuild, the OED has managed to maintain its status as the most reputed dictionary in British English.

In the following section we will depart from Steiner's 1970 seminal work to offer a brief survey on bilingual English-Spanish lexicography between the sixteenth and the 
nineteenth century due to the fact that, as mentioned in previous pages, the Latin influence in British lexicographical practice is really significant.

A glossary of around 1100 entries by Antonio de Corro, who was the tutor of Henry IV of France, is considered to be the first lexicographical bilingual work in English and Spanish. Although written ca.1560, it was published some decades later in England entitled Grammatical Rules to Learn the French and Spanish Languages. Probably inspired by this compilation, Richard Percyvall published a dictionary in 1591 which acted as a prologue to the aforementioned volume, although it was almost five times larger than the actual grammatical compilation. This work may be taken to be the first serious attempt at producing a bilingual English-Spanish dictionary heavily influenced by the works of Nebrija, something which can also be seen in the prologues of different volumes from the period. As far as Percyvall's study is concerned, he follows an alphabetical structure similar to that of the Spanish scholar, although he simplifies the different entries of each headword (Steiner 1970: 20). However, as the Spanish Empire starts its downfall and the British Empire flourishes from the AngloSpanish War of 1585-1604 onwards, the first exclusively monolingual English dictionaries begin to be printed.

Despite their obvious didactic purpose, Béjoint (1994) notes that from the seventeenth century on, an evolution towards what we label today as 'dictionaries of usage' starts. These are characterised by a wider range of headwords, which are introduced for reasons that fall well beyond purely commercial interests. As it happened with contemporary Spanish or French dictionaries, the general aim was to reflect a rule that would avoid the corruption of the different terms in order to maintain the purity of the language. Thus, the dictionaries of 'authority', that is, those which exemplify the use of a certain entry by means of excerpts taken from the most significant works in the language, can also be found in the history of English lexicography. Such is the case of the previously mentioned $O E D$, which will be primarily used in this work due to the fact that it offers a diachronic survey on the evolution of some words by means of an exploration of the textual appearances of its headwords. Finally, to put an end to this brief overview, it might be interesting to note that there also exists a historically recent yet highly prolific lexicographic tradition in the United States, thanks to the publication of the Webster's Third New International Dictionary, which would constitute a fantastic corpus to carry out a similar study to one proposed by this article, but from a NorthAmerican perspective.

\subsection{Description of the dictionaries used in the study}

The present study has focused on dictionaries from the 1980s because the publication of two representative works of the institutional lexicographic tradition in both countries takes place during this period. Despite the fact that both the United Kingdom and Spain enjoy a long lexicographic tradition, it is only in 1989 that Oxford publishes what was to become the epitome of English lexicography, the second edition of their $O E D$, comprising a total of twenty volumes that encapsulate more than 500,000 definitions. 
This work constitutes a major step towards the modernisation of one of the most influential dictionaries in the English tradition since it represents a revolution in the way in which dictionaries were conceived, as Béjoint (1994) acknowledges when he clarifies that even though most of the 1928 volume's definitions were maintained, they were also significantly expanded and completed.

Published for the first time in twelve volumes under the title A New English Dictionary on Historical Principles in 1928, the OED has been the subject of numerous revisions and has inspired many historic dictionaries ever since its beginnings. Already in 1933 an updated version, entitled Oxford English Dictionary on Historical Principles and containing a supplementary thirteenth volume, was printed. The working methodology employed was based on signalling the words' etymology (as we can infer from the titles of these first volumes) following a chronological arrangement in polysemic entries. The sources employed stem from a primarily literary corpus, with texts from Shakespeare, Walter Scott and Chaucer, including a wide range of quotations and examples that typified the majority of senses of each headword. Finally, it is important to mention that no Christian names or illustrations are included.

Given the fact that one of the most revised versions of the DRAE was published in 1984, we have deemed it interesting to carry out this comparative study between both editions of the $O E D$ and the $D R A E$ in order to ascertain any possible parallelisms and divergences that may exist and why. Thanks to the task carried out by the RAE when they uploaded online a free-access version of the Nuevo Tesoro Lexicográfico de la Lengua Española, it is possible to look up all the dictionaries published by this institution online, from the first Diccionario de autoridades (1726-1739) to the latest edition - the twenty-first one - which includes amendments to be implemented in future editions.

It has already been mentioned that the main purpose of this study is to do a comprehensive analysis of the possible religious or confessional focalisation to be found in the microstructure of the two aforementioned dictionaries, the $O E D$ and the $D R A E$. Hence, the following section will focus on the various strategies that are used in these dictionaries, strategies which have been deduced from the comparison of the selected corpus of religious terms, which is included as an appendix to this study. Some of the commentaries that will be made in the following pages will make reference to diachronic aspects which may be relevant in terms of the ideological charge found in the headwords' definition.

\section{Analysis of the different discursive strategies of focalisation}

For the analysis of the different microstructural discursive strategies that can be found in the two dictionaries that constitute the core of this article, we have followed a classification that will consider the background of definitions and the restrictions in meaning, together with the resources of discursive modalisation. These will be divided into epistemic, deontic, volitive and evaluative. Finally, the results stemming from the 
comparative analysis of the selected corpus will be explained, placing special emphasis on the dichotomic character on which this study's hypothesis relies. Before moving on to commenting on a few examples, it may be significant to mention that most of the definitions under study present more than one aspect of modalisation at the same time. For this reason, we will attempt to point out or highlight the most relevant one in relation to the specific headword in each case.

No references to the order of the different entries examined in this work will be made during the development of our argument, since doing that would automatically imply to make reference to the order of the various meanings as of their diatopic, diastratic and diaphasic markers, something which falls out of the scope of the present article. However, such a detailed reference could form the basis of some future research in that area.

\subsection{Modalisation in the environ of the definition and meaning restrictions}

One of the most outstanding peculiarities to be found among the strategies employed in the 1984 edition of the DRAE and the 1989 edition of the $O E D$ is the way in which the meaning and scope of religious terms are restricted. On the one hand, the DRAE maintains the tendency to capitalise the word Iglesia (Church) to refer exclusively to the Roman Catholic Church, thus leaving out of the definition any other religions, an inclination which can also be found in the definition of the word acólito (acolyte), whose headword reads 'minister of the Church'. ${ }^{4}$ Although it might be argued that the use of the capital letter can be considered as an instance of exclusive reference to the Roman Catholic Church, the inclusion of such a letter at this point also stands out as an example of religious focalisation on the dictionary's part, thus assuming that its readers will automatically feel included within the religious group from which the dictionary positions itself in moral and cultural terms. On the other hand, the definition of acolyte provided by the $O E D$ exemplifies the application of a diametrically opposed strategy, since no capitalisation is found whatsoever and we merely read 'an inferior officer in the church'. Therefore, the $O E D$ manages to change focus and shifts the defining weight of the word from the religious cult itself to the building or institution. We can deduce such a claim because the $O E D$ does capitalise other words of similar usage, but only those which refer to the Christian Church in general, consequently including the Anglican faith in them. This is precisely what happens in the definition of catholic, which appears as 'of a church or churches now taken to represent the primitive Church'. This modalising strategy, which narrows down the environ of the definition, is present in a great variety of examples that follow the same pattern in both dictionaries, that is, the DRAE tends to use capital letters without any indefinite articles so as to refer to the Roman Catholic Church, whereas the OED employs the same capitalisation to widen the scope and refer to the Christian Church, hence clearly delimitating the perspective from which we speak and read.

Additionally, it seems to be fairly common to insert extra comments in an explanatory way so as to restrict the meaning of a definition, as it happens with the 
terms ascensión (ascension) and asunción (the Assumption). In both instances the definition starts by por excelencia (par excellence), but to which excellence is the dictionary alluding? Even though the sentence may seem harmless, it does point to the Roman Catholic tradition in a subtle way, although the lexicographers avoid doing so in an open way to endow the definition with an air of universality. The DRAE's positioning in this case is coherent with what has been commented upon in the case of Iglesia (Church) or acólito (acolyte), when it considers that the implicit reader will know how to recognise that excellence or universality of which the definition speaks, thus assuming that the implicit Roman Catholic faith will be shared by all those who approach the dictionary. Quite oppositely, the strategy employed by the $O E D$ is much more specific, because each definition is narrowed down by making specific (and not underlying or intrinsic) reference to the type of cults with which the word is related. Such is the case of the headword angel, whose definition starts by 'according to Jewish, Christian, Mohammedan, and other theologies', consequently opening up the definition to alternative religious interpretations of the term.

Finally, it is worth commenting upon a set of cases in which less explicit strategies are used by the $O E D$ 's lexicographers, and which indirectly imply a sceptical positioning in relation to certain practices or religious traditions. These strategies rely on the use of verb forms like claiming or supposed in definitions like that of catholic, already commented upon, or that of limbo, which reads 'a region supposed to exist', hence questioning their actual existence. Such a shade of meaning is not present at all in the DRAE's definition of this last word, where the limbo is automatically taken to be a universal truth by providing a clear "place or womb where the saints and the old patriarchs' souls were detained'.

As we have seen by means of these examples, it seems obvious that the $O E D$ attempts to distance itself from such religious-oriented definitions, and that the DRAE seeks to enforce them as verisimilar facts. Both practices hold an ideological connotation insofar as some sort of religious focalisation or other can be observed in relation to the cult within implicit authors inscribe themselves.

\subsection{Epistemic modalisation}

Epistemic modalisation marks the writer's level of adhesion to the text by means of a set of discursive strategies that manifest the belonging to a certain group. In the following examples, this belonging will be identified with the use of certain pronouns and demonstratives that focalise one's specific credo perspective, as it happens with the DRAE's definition of the word adviento (Advent), in which the form Nuestro Señor (Our Lord) is employed. Even though we may consider such a construction to be a lexicalised structure, the ideological connotations borne by the capital letters cannot be underestimated. These obviously refer back to the same problem as the one inherent to Iglesia (Church), hence exemplifying the implicit author's positioning from within a specific collective, and his/her assumption that prospective readers will share the same code or set of beliefs associated with that collective. The definition for paraiso 
(paradise) and dogma exemplify this tendency once again, since the DRAE claims that the former is the location where 'God placed our first father' and the latter constitutes a truth 'proposed by the Church for us to believe'. This final case is especially useful as it implicitly excludes any other kind of definite religious consideration outside the Roman Catholic one whilst, at the same time, the pronominal use reinforces the feeling of belonging to a shared cultural background.

Something similar occurs with the OED's definitions of altar and puritan, which include exclusive pronouns and demonstratives like 'those', 'that', or 'they', employed to gain distance from the group to which the definitions of such religious terms make reference, hence excluding prospective readers from it. Consequently, an altar is referred to as being used 'in those Christian Churches which celebrate the Eucharist or communion service as a sacrifice', whereas a puritan is qualified as 'a member of that party of English Protestants who regarded the reformation of the church under Elizabeth as incomplete'. What seems to be clear is that both the OED and the DRAE make use of epistemic modalisation, positioning themselves within a given religious group by means of pronouns and demonstratives.

As far as epistemic modalisation is concerned, there are times when the strategy followed by the dictionaries which are being studied is significantly different. In some occasions, the DRAE chooses to openly focalise the discourse from a Roman Catholic perspective while the $O E D$ remains willingly neutral by means of using impersonal structures. The case of conciencia (conscience) illustrates most clearly this tendency, as the $O E D$ describes it by using the impersonal form as 'the moral quality of one's motives and actions', in contrast to the DRAE's conjugation of the verb form in 'internal knowledge of the good that we should do', thus inscribing both the implicit author and the reader within a religious group which theoretically shares the same moral principles. Such a strategy is very commonly employed by the DRAE, as it can be deduced from the definitions of esperanza (hope) or papista (papist). In relation to this last word, it is important to mention that a curious dichotomic focalisation is found in its definition since the term was originally created in an Anglican environment to refer to Roman Catholics. Despite the apparently neutral spirit of the $O E D$ 's definition, ideology pours in in a bracketed comment at the end, '(usually hostile or opprobrious) ', which expands the term's scope by inserting an evaluative clarification. Nevertheless, the most significant religious focalisation in relation to this term is the one offered by the DRAE, which defines papista (papist) as the 'name that heretics and schismatics give to Roman Catholics', a clearly ideological statement which is reinforced by the introduction of the conjugated 3rd person plural form of the verb in the Spanish original ('nombre que herejes y cismáticos dan al católico romano') together with the clearly pejorative nature of the epithets with which Anglican people are referred to.

\subsection{Deontic Modalisation}

When it comes to dealing with deontic modalisation in our study, that is, the use of hyperonyms that relate a given term to the world it belongs, it is important to point out 
the positive valorisation performed by the DRAE by means of the word virtud (virtue), consistently applied to those headwords that are considered as having positive qualities from a Christian standpoint. In fact, this strategy is used to relate religious terms to their realm of application in a positive way, qualifying words like abstinencia (abstinence) or castidad (chastity) as virtues or good attitudes to be followed and thus failing to note that they are religious habits, that is to say, without acknowledging their being habits restricted to a specific context.

In spite of the fact that the definitions offered by the $O E D$ seem to be free from this modalising ideology at first sight, it might be important to highlight the use of some words. For instance, in the case of words like forbearance or purity, these seem to lack the obvious theological specific weight of virtue and carry some degree of implicit characterisation that does not acknowledge the religious focalisation being undertaken. However, in general terms, it seems safe to assume that the $O E D$ prefers to maintain a certain degree of religious scepticism in relation to deontic modalisation, including clarifications in the environ of the definition by means of restrictive markers that help narrow down to the religious realm the implications of certain terms, as in the case of hope, which is defined as a 'biblical archaism'.

\subsection{Volitive Modalisation}

Volitive modalisation implies that a subjective judgement is being made through a focalisation of what is desirable and what is not. In this section we will reintroduce one of the aforementioned definitions, that of the word conciencia (conscience), which appears in the DRAE as the 'internal knowledge of the good that we should do and the evil that we should avoid'. Apart from the aforementioned implications stemming from verbal conjugation and the use of an impersonal form the $O E D$ 's definitions, it could be really useful at this point of our exploration of religious focalisation to single out the implicit judgement done by the $D R A E$ at considering itself with enough moral stature to value what should and should not be done. Once again, it is vital to remember that such a claim is made from a religious perspective and not from a general one, so that the $D R A E$ ends up bringing a moralising religious discourse into the definition and inscribing itself within the collective by means of the verbal form 'we should'.

The most striking definition in terms of its volitive charge in both dictionaries is that of the term sodomía/sodomy. On the one hand, the DRAE defines this headword as the 'copulation between males or against the natural order', thus adding a second element after the conjunction that introduces an ideological consideration which focalises the discourse from the perspective of someone who considers same-sex relationships to be undesirable. The modalisation which is being carried out after the conjunction could very well be avoided, but the fact that it is included indicates a need on the implicit author's part to make his/her position clear in relation to the implications of the term.

The same mechanism is at work in the OED's definition of sodomy, which reads 'the unnatural form of sexual intercourse', consequently ascribing to this sexual practice 
the same negative value as the DRAE. Doubtlessly, this example from both dictionaries demonstrates a clear volitive modalisation, not only religious perspective, but also social and cultural point of view insofar as it considers sodomy a negative trait, making it clear that the focalised discourse stands from a heterosexual perspective.

\subsection{Evaluative modalisation}

In dictionaries, evaluative modalisation is performed by means of pejorative comments, exaggerations and superlative forms, together with a profuse application of adverbs and adjectives. The instances in which pejorative comments are inserted in the definition are fairly common, especially in the case of the $D R A E$. The very definition of the headword secta (sect) should be enough to clarify this point, since the aforementioned dictionary claims that a secta is 'a religious partiality [...] of those faithful to a religion which the speaker considers to be false'. Thus, if we consider the dictionary as a specific kind of discourse, it seems safe to state that the $D R A E$ is positioning itself quite openly against this term by declaring that this term will be used from that moment onwards to refer to those ideologies deemed to be false. What is more, this is made even more evident in the definition provided for pagano (pagan) which, according to the DRAE, refers to 'Mohammedans and other monotheist sectarians, and even all those unbaptised infidels'.

Following a more generalising strategy, the OED's definition of sect makes reference to 'a religious order [...] applied to any of the main religions of the world, as Christianity, Judaism, or Islam'. Therefore, the dichotomic gap between the evaluative implications in both dictionaries has to be considered as an important divergence, especially in the light of what is being seen in this section. Since the focus of the present study is to consider ideological and religious focalisation either from a Roman Catholic standpoint (in the $D R A E$ ) and from an Anglican one (in the $O E D$ ), it does seem obvious to assume that the former uses the word sect as a negative term in most environments where the $O E D$ simply employs the words doctrine and even religion in an attempt to free the definition from any type of evaluative charge. Examples like that of mahometano/Mohammedan are especially interesting to mention at this point, given the fact that whereas the $D R A E$ defines it as 'he/she who professes the sect of Muhammad', the $O E D$ merely states 'of or pertaining to Muhammad, or to the religion or doctrine of Muhammad'. Bearing these examples in mind, we may argue that religious focalisation is more evident in the DRAE's case than in the OED's one, although both dictionaries make use of evaluative modalisation at times. The main difference to be found between both is linked to the use and realm of application of terms like religion/religion, secta/sect and doctrina/doctrine. In these cases, the $O E D$ tries to maintain a more conciliating and respectful mood in relation to other religions by means of not performing any evaluative modalisation in their definition, something which, as we have seen, is diametrically different in the $D R A E$. 


\subsubsection{Pejorative comments}

This subsection is closely related to some of the main conclusions drawn from our analysis of volitive modalisation, since this discursive strategy serves to the purpose of discrediting those aspects which are considered undesirable by the implicit author. There are some occasions in which both the DRAE and the OED restrict the meaning of some words by means of the combination of these pejorative comments with an effective delimitation of the definition's environ, as it happens in both texts with the words sinagoga/synagogue. That way, the DRAE defines the word as 'in pejorative sense, meeting with illicit purposes' whilst the $O E D$ states that it can be considered to be 'in hostile controversial use [...] Synagogue of Satan'. In spite of the inclusion of this restriction that helps to identify the pejorative sense given to this word in some contexts, there can be no doubt regarding the specific ideological charge present in it: the discourse is focalised from the outside so as to gain distance from the religious group to which the headword relates.

One of the most flagrant instances of definitions which sport pejorative comments is that of the $O E D$ 's apostate, which is labelled in this dictionary as 'a pervert', in clear contrast to the DRAE, which provides the more neutral 'he/she who commits apostasy'. We may deduce that the negative connotation offered by the $O E D$ stems from the fact that apostate is morally corrupt insofar as he/she does not accept the faith and moral precepts of the group in which the implicit author positions him/herself.

\subsubsection{Exaggerations and superlative forms}

Religious terms are often defined by means of superlatives, as it occurs in the DRAE's definition of paraíso (paradise), referred to as a 'most pleasant place'. However, the most common tendency is to define such terms through the use of metaphors that offer a somehow exaggerated and positively distorted view. This is the case of the $O E D$ 's defiition of paradise as 'the garden of Eden' or the more obvious one of cielo (heaven), which the DRAE considers to be 'the mansion where the angels, saints and the blessed enjoy the presence of God'. These flamboyant narrative strategies inevitably connect the dictionary's discourse to that of the Bible, hence offering a clear religious focalisation by employing the Christian imaginary in the description of terms like the previously mentioned ones.

\subsubsection{Use of adverbs and adjectives}

In order to finish our exploration of the modalising strategies by means of the focalisation of religious terms in dictionaries, we will briefly comment upon the appearance of adverbs and adjectives in the microstructure of the two dictionaries under studied. It is quite frequent to find these types of words used either to boost those positive aspects of terms like devoción (devotion), characterised by the DRAE as a 'good habit'; or to heighten the negative connotations to be found in a long list of words 
like ídolo (idol) or santería (santería), which are respectively qualified by means of adjectives like 'false deity' or 'indiscreet and superstitious cult'. However, the most interesting use of this strategy is to be found in the $O E D$ 's definition of Anglicanism, considered to be 'the genuine representative of the Catholic Church', thus legitimising the Anglicans' position as the authentic branch within the Catholic Church and ultimately focalising the discourse from a superior perspective in relation to any other confession, including the Roman Catholic one. Of course, the DRAE's perspective is very different as far as Anglicanism is concerned, relegating their influence as being the 'group of doctrines following the reformed religion which predominates in England'. Given the examples presented in this article, one might expect to get a similarly grandiloquent definition of catolicismo (Catholicism) from the DRAE. However, the Spanish dictionary is surprisingly neutral in this sense when it states that Catholicism in the Hispanic sense of the word, that is, Roman Catholicism - is the 'community and universal guild of those who profess Catholic faith'. Nevertheless, the connotations held by universal do somehow ascribe a superior quality to this confession and perfectly exemplify the modalising role played by adjectives and adverbs that has been discussed in this section.

\section{Discussion of the results}

As our results seem to attest, there exists a considerable degree of religious focalisation in both dictionaries which needs to be addressed so as to fully understand the mechanisms that operate behind this manipulation of the language in a supposedly neutral book, as a dictionary should be. Previous sections of this work have reflected on the close relationship between dictionary, ideology and the culture in which such volume is produced. Hence, we must note that all the religious focalisations presented here do not stem from a willingly conscious distorting strategy, but rather they are the product of sociocognitive considerations, embodied in the biased models of representation that give grounds to the different definitions provided.

The scope of religious terms is effectively restricted in both dictionaries, which employ a variety of strategies to reduce the connotative and denotative meaning of each term. Such is the case of the DRAE's Iglesia (Church), whose capital letter reduces all possible meanings to the one and only church within the Spanish context, that is, the Roman Catholic one. Quite oppositely, the $O E D$ only capitalises Church in the definition it provides of catholic, where it is used to refer to the Christian Church which encapsulates all major religious branches. This example perfectly reflects the way in which a simple letter may change the way in which we perceive a given institution.

Among the strategies that may be utilised to restrict meaning in the definition's environ, the DRAE makes extensive use of extra comments which are inserted at the beginning or at the end of the definition. These produce a slight alteration on the rest of the sentence, as the definitions of ascensión (ascension) and asunción (the Assumption) attest to. The fact that they are both modified by 'par excellence' implies a 
legitimisation of the Roman Catholic tradition, assuming that prospective readers will not question whether that excellence is indeed a real quality. Whereas this modifying value found in the $D R A E$ can be perceived as underlying the definition, the $O E D$ is more direct in its use of extra comments. This is achieved after inserting extra information that makes reference to specific religious cults rather than assuming that the prospective reader and the prospective author share a religious background to which 'par excellence' means the same. As we have mentioned, this is seen quite well in the definition of angel, which alludes to the Jewish, Christian and Mohammedan traditions. Nevertheless, the $O E D$ and DRAE share a tendency to insert extra comments with evaluative verbs like suppose or believe.

Epistemic modalisation is perhaps the most obvious marker of religious focalisation in the two dictionaries since both make abundant use of pronouns that highlight the belonging to a given group, which the dictionary wishes to either gain distance from or be included in. Thus, adviento (Advent) is referred to as the preparation for Our Lord's arrival, automatically assuming a common membership which is emphasised by the pronoun our. In the same way, the OED's definitions of altar (in those Christian Churches...) and puritan (a member of that party of...) contain pronouns that serve to the purpose of lessening the prospective author's religious attachment to a specific group.

The use of hyperonyms to ascribe either positive or negative connotations to certain terms which are deemed respectively desirable or undesirable is perhaps best exemplified by the DRAE's definition of abstinencia (abstinence), which is depicted as a positive virtue to be pursued. In close connection to this comes the volitive modalisation performed in words like sodomía/sodomy, where both dictionaries consider themselves morally justified in providing a definition (be it the Spanish 'the copulation between males or against the natural order' or the English 'the unnatural form of sexual intercourse'), emphasising the ideological consideration that homosexual relationships are unnatural. The Spanish definition goes a little further by using the form 'natural order', hence providing a clear connotation of immorality.

Let us now move on to discussing the ways in which evaluative modalisation is applied in both dictionaries, which is perhaps one of the most productive areas as far as our research is concerned. Both dictionaries employ a variety of evaluative strategies so as to endow their definitions with a degree of religious focalisation; however, we must note that, once again, the $D R A E$ is much more obvious and drastic in its judgements than its English counterpart. Thus, in the Spanish dictionary the word secta (sect) is defined as comprising 'even all those unbaptised infidels', among others, whereas the English $O E D$ levels religious considerations and claims that it refers to 'a religious order [...] applied to any of the main religions of the world'. Implicit judgements can come in the form of open statements - such as the ones we have just discussed - in the form of clarifications regarding the pejorative use of some terms, or in the application of superlative forms, adjectives and adverbs to a given headword. In the first case, the references of both dictionaries seem to be consistent to pejorative uses of the word being discussed by usually inserting a clarification like 'in a pejorative sense' or 'in a 
hostile sense', thus gaining distance from the question of whether they agree with such sense or not. As far as the use of superlatives, adjectives and adverbs is concerned, it is significant to mention that both dictionaries present similar strategies to preach on what is good and what should be avoided, therefore supporting our thesis regarding the ideological value of dictionaries as vehicles for moral critique. This can be seen in the $O E D$ 's definition of heaven, referred to with the idyllic 'garden of Eden', whereas the $D R A E$ is more straightforward and characterises it as 'a most pleasant place'. Such technique can also be seen in the DRAE's definition of devoción (devotion), typified as 'a good habit'.

As far as religious modalisation is concerned, what remains clear is that, despite the fact that both dictionaries make use of similar strategies at different points of their texts, the religious charge is much heavier in the DRAE than in the OED, which seems to remain more neutral in most of its entries. The reasons behind the higher degree of religiosity, so to say, to be found in the Spanish dictionary may lie in socio-cultural factors. After all, we need to consider that the DRAE was published in 1984, when Spain was still adjusting after almost forty years of dictatorship and consequently most of the cultivated classes - the potential users of the dictionary - would still be attached to religion in a higher degree than their Anglo-Saxon counterparts. What is more, we should not forget that the OED's version dates from 1989, at the end of a decade which consistently questioned religious dogmas in the United Kingdom. However, the most important aspect to take into account is that, however slight it may be, religious focalisation is present in both dictionaries, mirroring the culture in which they are produced, as the definitions of Anglicanism or Catholicism ultimately prove.

\section{Conclusions}

There are two major perspectives from which the dictionary has been traditionally considered: on the one hand, there are those who venerate it, revering it as a sign of culture and, thus, automatically establishing the connection that the larger the dictionary, the more cultivated its users may be. Gates (1992: 273) reflects on this quality of the dictionary as a moral authority, together with the desire that 'words on its pages be good and suitable for most circumstances'. On the other hand, there are those who consider it as an effective mirror from which to contemplate the target language and, by extension, the target culture which motivates its definitions. In 1970, Dubois claimed that the dictionary was far from being an artefact or linguistic product; rather, he considered it as being, above all, a finite and continuous discourse on language which the lexicographer maintains with the aim of orienting the reader in its use and norm.

The usefulness of dictionaries as didactic tools has been readily recognised by most scholars throughout the ages. It has been only from the 1950s onwards that the effort of some lexicographers concerned with the theoretical aspects of their work has given rise to a deeper structuring of lexicography, as well as to a wider 
acknowledgment of the various concerns that may operate in its elaboration, namely semantic, pragmatic and discursive. As a result, the users' perception of the dictionary has become more accurate, and so have the ways in which ideological discourse is introduced in the dictionary. Its potential as an effective shaper of thoughts and human realities has been often disregarded for the sake of higher interests, be them political, sociocultural or even commercial. More recently, studies like those of Ball (1998) have reflected on one of the very motivations of the present study, i.e. the way in which both prospective authors and readers focalise the words to either inscribe themselves within a given group (the previously mentioned in-groups) or to gain distance from it (outgroups), inferring the troublesome term with negative or undesired connotations.

After the detailed description, analysis and discussion of the different definitions belonging to the corpus of religious terms that have been selected for this study, what remains clear is that both the DRAE and the $O E D$ do practice an obvious modalisation of the discourse at the microstructure of their texts. The plausible focalisation that motivated this study has been proven to be a reality in both dictionaries, executed by means of a variety of discursive resources that offer at times a shared Christian perspective due to the common origin of both the Anglican and the Roman Catholic confessions. Therefore, it is not surprising to acknowledge the fact that both texts use similar discursive strategies when it comes to analysing some headwords which go in opposition to Christian tradition, be it either by using pronouns to gain distance from them or by employing a deontic or volitive modalisation to focalise the discourse from a positivist perspective. Nonetheless, some outstanding differences in the strategies used by the dictionaries are found, especially if we take into account the $D R A E$ 's preference for metonymic expressions, which are substituted in the $O E D$ by explanatory extra comments which are sometimes placed in the periphery of the definition. Moreover, we can acknowledge a wider use of impersonality in the $O E D$ than in the $D R A E$, due to the fact that the later tends to position itself more openly against other cults in its definitions. Generally speaking, however, we may claim that an evident Christian focalisation can be observed in both texts, which drifts from Roman Catholicism in the case of the DRAE to Anglicanism in the OED's one, in those instances where such specification is deemed suitable in order to gain distance from or include the prospective reader in the discourse of both dictionaries.

As we have discussed, a comparative study between monolingual dictionaries from different lexicographic traditions has given highly meaningful results, which may form the basis of some future research with similar motivation that may, perhaps, carry out a more concise diachronic survey so as to study the possible evolution of ideological markers in the dictionaries' discourse that will surely open up new avenues of research in the field of lexicography. 


\section{Notes}

* María Alonso Alonso gratefully acknowledges the Universidade de Vigo for the awarding of a grant to support the research relevant to the preparation of this article.

1. It is important to clarify that, as we have already mentioned, a homonymous entity to the Real Academia Española does not exist in the Anglo-Saxon tradition. Therefore, we have used the term institutional to refer, on the one hand, to the Diccionario de la Real Academia Española and, on the other, to the Oxford English Dictionary as its British institutional counterpart.

2. The study of glosses, conversation manuals and grammar books will be willingly disregarded, due to their being object of a future research project.

3. The complete title of this book is Compendio de algunos vocablos arábigos introduzidos en la lengua Castellana en alguna manera corruptos, de que comúnmente usamos, puestos por orden alfabético. (A Compendium of some Arabic voices introduced in the Spanish language, which are somehow corrupt and commonly used, arranged in alphabetical order) [our translation].

4. For the sake of brevity, in this section we have translated into English all the definitions taken from the DRAE.

\section{References}

Aliaga Jiménez, José Luis (2000): "La macro y microestructura de un diccionario no sexista y no androcéntrico". In F. Nagore Laín, ed., Homenaje a Rafael Andoltz. Estudios sobre la Cultura Popular, la Tradición y la Lengua en Aragón. Zaragoza: Instituto de Estudios Aragoneses, 457-476.

Anglada Boix, Emilia (1991): "Lexicografía, metalexicografía, diccionario y discurso". Sintagma 3: 5-11.

Azorín, Dolores and M. Isabel Santamaría (2004): “El Diccionario de Autoridades (17261739) y el Diccionario castellano (1786-1793) de Terreros y Pando ante la recepción de las voces de especialidad". Revista de Investigación Lingüística 7: 171-192.

Ball, Matthew (1998): Dictionaries and Ideology: The treatment of Gays, Lesbians and Bisexuals in Lexicographic Works. Unpublished MA thesis: University of Ottawa.

Beaujot, Jean-Pierre (1989): "Dictionnaire et ideologies". In F.J. Hausmann et al., eds., Dictionaries : An International Encyclopedia of Lexicography. Berlin: de Gruyter, 7988.

Béjoint, Henri (1994): Tradition and Innovation in Modern English Dictionaries. Oxford: Clarendon Press.

Chomsky, Noam (1968): Language and Mind. New York: Harcourt.

Dubois, Jean (1970): "Dictionnaire et discours didactique". Langages 19: 35-47.

Fiske, Susan T. and Shelley E. Taylor (1991): Social cognition. New York: McGraw Hill.

Forgas Berdet, Esther (2007): "Diccionarios e Ideologías". Interlingüística 17: 2-16.

Gates, Edward (1992): "Should a dictionary include only the good words?". In K. HyldgaardJensen and Arne Zettersten, eds., Symposium on Lexicography V. Tübingen: Max Niemeyer Verlag, 265-280. 
Geeraerts, Dirk (2007): The Oxford Handbook of Cognitive Linguistics. New York: Oxford University Press.

Hamilton, David and Jeffrey W. Sherman (1994): "Stereotypes". In R. S. Wyer, Jr. and T. K. Srull, eds., Handbook of Social Cognition. Hillsdale, NJ: Erlbaum, 1-68.

Hernández Hernández, Humberto (1991): "Sobre el concepto de acepción": Revisiones y propuestas". Voz y Letra 1: 127-141.

Johnson, Allan G (1995): The Blackwell Dictionary of Sociology. Cambridge, MA: Blackwell Reference.

Marcos Marín, Francisco (1980): Curso de gramática española. Madrid: Cincel/Kapelusz.

Medina Guerra, M. Antonia (2003): Lexicografía española. Barcelona: Ariel.

Osselton, Noel (2008): "The Early Development of the English Monolingual Dictionary Seventeenth and Early Eighteenthth Centuries". In A.P. Cowie, ed., The Oxford History of English Lexicography. Oxford: Oxford University Press, 131-155.

Oxford English Dictionary. (1989). 2nd ed. Oxford: Clarendon Press.

Quemada, Bernard (1987): "Notes sur lexicographie et dictionnairique". Cahiers de lexicologie 51, 2: 229-242

Real Academia Española (1984): Diccionario de la Real Academia Española. Madrid: EspasaCalpe. (2001): Nuevo Tesoro Lexicográfico de la Lengua Española. Madrid: Espasa-Calpe.

Rey, Alain and Simone Delesalle (1979): "Problèmes et conflits lexicographiques". Langue française 43: 4-26.

Rodríguez Barcia, Susana (2005): "Génesis de la lexicografía monolingüe española". Unpublished $\mathrm{PhD}$ thesis: Universidade de Vigo.

(2004): "El léxico religioso en el Diccionario de Autoridades (1726-1739)". In C.J. Corrales Zumbado et al., eds., Nuevas aportaciones a la historiografía lingüística. Actas del IV congreso internacional de la SEHL. Madrid: Arco Libros, 1417-1426.

Sánchez García, Francisco J (2009): El léxico religioso en los diccionarios de la Real Academia Española. Barcelona: Publicacions i Edicions Universitat de Barcelona.

Slobin, Dan (1987): "From 'Thought and Language' to 'Thinking for Speaking"'. Proceedings of the Berkeley Linguistic Society 13: 435-445.

Steiner, Roger J (1970): Two Centuries of Spanish and English Bilingual Lexicography 1590 1800. Paris: Mouton.

Trujillo, Ramón (1994): "El diccionario frente a la semántica". In Humberto Hernández Hernández, ed., Aspectos de lexicografía contemporánea. Barcelona: Biblograf, 73-93.

van Dijk, Teun A. (2005): "Ideología y análisis del discurso". Revista Internacional de Filosofía Iberoamericana y Teoría Social 29: 9-36. (1996): "Análisis del discurso ideológico". Versión 6: 15-43. (1995): "Discourse Semantics and Ideology". Discourse and Society 6, 2: 243-289. 